\title{
Characteristics of Early Marriages
}

\section{Authors: Kasey J. Eickmeyer \& Paul Hemez}

The age at first marriage has risen steadily since the 1950s (FP-16-07). In 2015, about half of all women married by age 28, and half of men did so by 30 (FP-16-07). In this profile, we compare the characteristics of men and women in early marriages (marriages in which both members were younger than twenty-five) to those in later marriages (marriages in which at least one partner was twenty-five or older). Using the 2015 American Community Survey (ACS) and the 2011-2015 National Survey of Family Growth (NSFG), we focus on the educational attainment, race and ethnicity, premarital cohabitation, and fertility behaviors of recently married individuals in different-sex marriages. The ACS represents marriages in the last year, and the NSFG data represents marriages since 2010.

- Among marriages formed in the past year (as measured in 2015), for the first time (i.e., neither was previously married), early marriages constituted about $17 \%$ of recent marriages.

- Among marriages in which both the bride and groom were married $11 \%$ were early marriages (Figure 1 ) a slight decline from 14\% in 2008 (not shown).

\section{$11 \%$ of recent marriages were early marriages}

\section{Educational Attainment}

- Nearly 1 out of 5 marriages among those with less than a high school degree was an early marriage, whereas only $7 \%$ of marriages occurring among individuals with a Bachelor's degree or more were early marriages.

o The share of early marriages among those with less than a high school degree was over twice as large as those with a Bachelor's degree or more.

Figure 2. Percentage of Early Marriages Among Those Who Married in the Past 12 Months by Educational Attainment, 2015

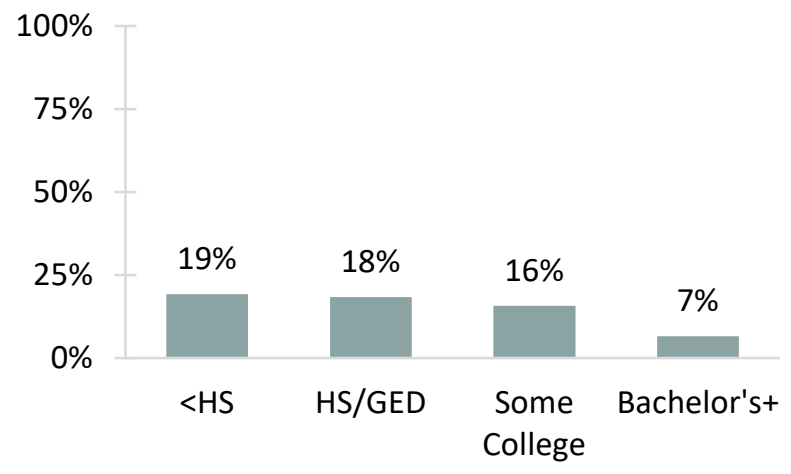

Source: NCFMR analyses of U.S. Census Bureau, American Community Survey 1-yr est.
Figure 1. Percentage of Early and Later Marriages Among Those Who Married in the Past 12 Months

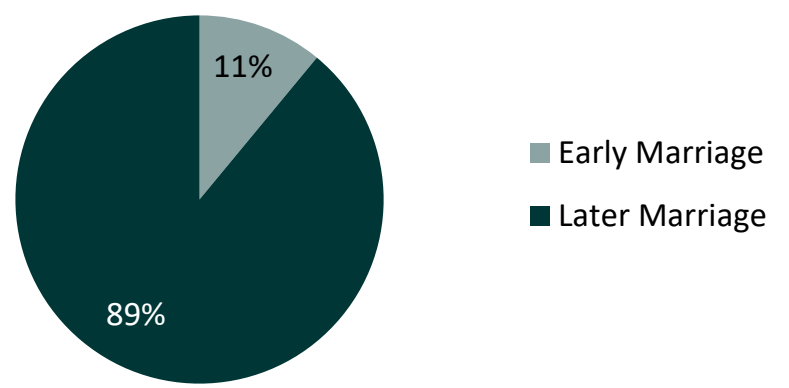

Source: NCFMR analyses of U.S. Census Bureau, 2015 American Community Survey 1-yr est

\section{Race and Ethnicity}

- Hispanics had the largest share (14\%) marrying early, followed by $12 \%$ of Whites.

- Asians had the smallest share in an early marriageonly 1 in 25 newlywed Asians were young adults under age twenty-five.

Figure 3. Percentage of Early Marriages Among Those Who Married in the Past 12 Months by Race/Ethnicity, 2015

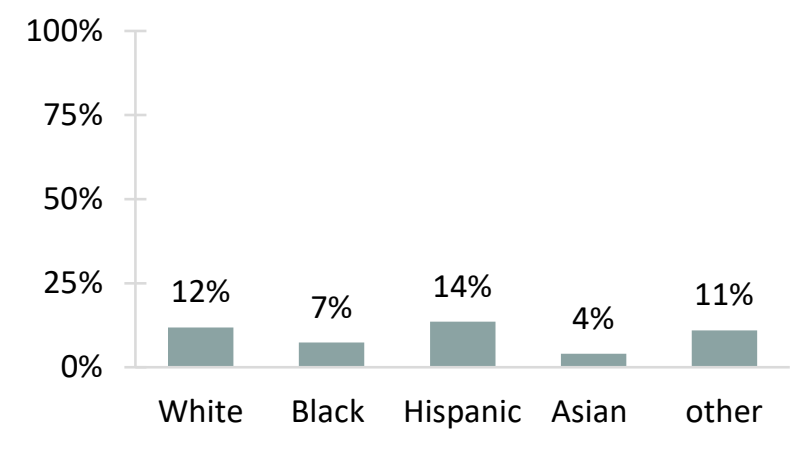

Source: NCFMR analyses of U.S. Census Bureau, American Community Survey 1-yr est. 


\section{Premarital Cohabitation}

- Among men and women who recently married, a majority had cohabited prior to marriage. However, a greater share of those in later marriages had cohabited (73\%) compared to those in early marriages (53\%).

Figure 4. Premarital Cohabitation Among Those Who Recently Married by Early vs. Later Marriages

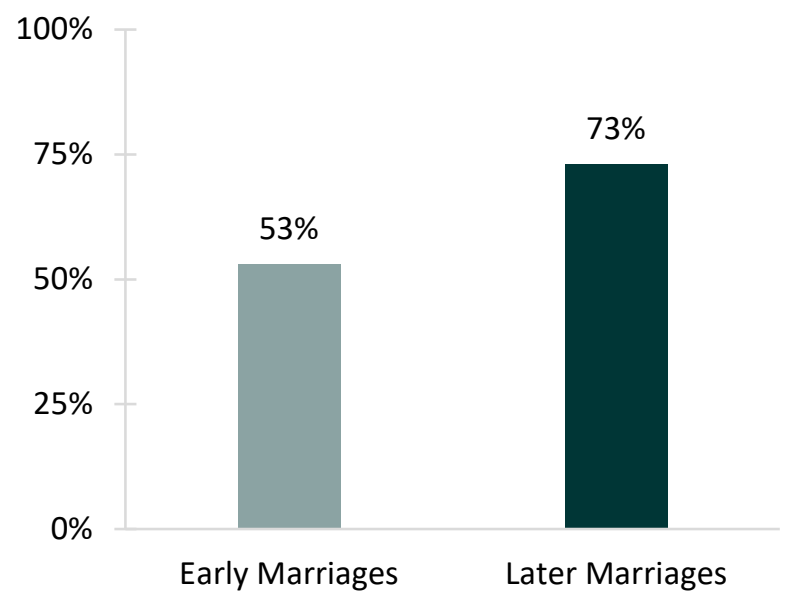

Source: NCFMR analyses of National Survey of Family Growth, 2011-2015 continuous data
Fertility Behaviors

- The share of newlywed women aged 15-44 in 2015 who had given birth within the past 12 months was nearly twice as large for those in early marriages (21 $\%)$ than later marriages ( $11 \%$ ) (ACS data not shown).

- A majority of women who recently married intended to have children. More women in early marriages (79\%) had intentions to have children than did women in later marriages (53\%).

Figure 5. Respondent "Intends to have (more) children" Among Those Who Recently Married by Early vs. Later Marriages

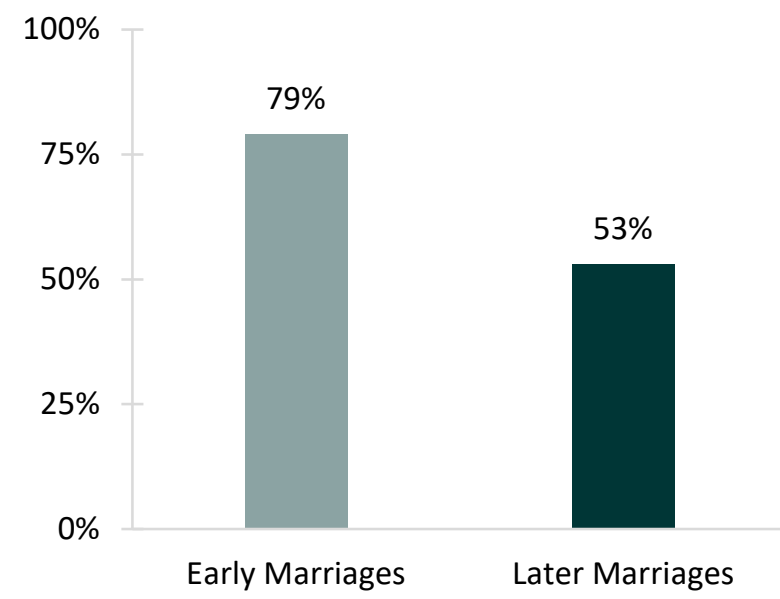

Source: NCFMR analyses of National Survey of Family Growth, 2011-2015 continuous data

\section{Data Sources:}

Ruggles, S., Genadek, K., Goeken, R., Grover, J., and Sobek, M. (2017). Integrated Public Use Microdata Series: Version 7.0 [dataset]. Minneapolis, MN: University of Minnesota, 2015. https://doi.org/10.18128ID010.V7.0

National Center for Health Statistics (NCHS). (2016). 2011-2015 National Survey of Family Growth Public Use Data and Documentation. Hyattsville, MD: CDC National Center for Health Statistics. Retrieved from http://www.cdc.gov/nchs/nsfg/index.htm

\section{References:}

Anderson, L. \& Payne, K. K. (2016). Median age at first marriage, 2014. Family Profiles, FP-16-07. Bowling Green, OH: National Center for Family \& Marriage Research. https://www.bgsu.ed u/ncfmr/resources/data/family-profiles/anderson-payne-median-age-first-ma rriage-fp16-07.html

\section{Suggested Citation:}

Eickmeyer, K. J., \& Hemez, P. (2017). Characteristics of early marriages. Family Profiles, FP-17-23. Bowling Green, OH: National Center for Family \& Marriage Research. https://doi.org/10.25035/ncfmr/fp-17-23 